\title{
El costumbrismo en la tonadilla escénica del siglo XVIII: El sistema de los preocupados, de Blas de Laserna
}

Costumbrism in the scenic tonadilla of the Eighteenth century: El sistema de los preocupados, by Blas de Laserna

IsMael LóPez MARTíN

Universidad de Extremadura https://orcid.org/0000-0002-5422-8540

CESXVIII, núm. 31 (2021), págs. 291-318 DOI: https://doi.org/10.17811/cesxviii.31.2021.291-318 ISSN: 1131-9879 ISSNe: 2697-0643
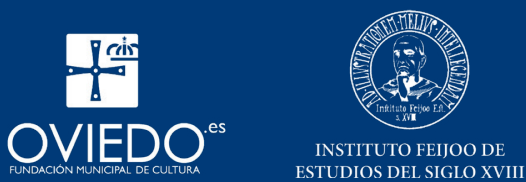


\section{RESUMEN}

Blas de Laserna (1751-1816) fue uno de los compositores más destacados de tonadillas escénicas durante la segunda mitad del siglo XVIII. Su pieza El sistema de los preocupados, cuyo guion con texto data de 1786, es una tonadilla a solo interpretada por la famosa soprano lírica Joaquina Arteaga que constituye uno de los ejemplos más notorios de las tonadillas satíricas que introducen el costumbrismo en su libreto. En este trabajo se propone la edición de dicha tonadilla y su estudio a partir de la estructura de la obra (entable, coplas, boleras y seguidillas) y de la crítica que recoge a la costumbre afrancesada de la preocupación y valoración de las apariencias (propia de la sociedad española de la época) con varios recursos.

Palabras clave

Tonadilla escénica, Blas de Laserna, El sistema de los preocupados, costumbrismo, preocupación, apariencias.

\section{ABSTRACT}

Blas de Laserna (1751-1816) was one of the most important composers of scenic tonadillas during the second half of the 18th century. The script with text of his play El sistema de los preocupados was written in 1786; it is a tonadilla a solo performed by the famous lyrical soprano Joaquina Arteaga. This is one of the most notorious examples of the satirical tonadillas that introduces costumbrism in their libretto. In this paper we propose the edition of this tonadilla and its study based on the structure of the play (entable, coplas, boleras, and seguidillas) as well as the criticism that includes the Frenchstyle custom of concern and valuation of appearances (characteristic of the Spanish society of the time) with various resources.

\section{KEY Words}

Scenic tonadilla, Blas de Laserna, El sistema de los preocupados, costumbrism, concern, appearances.

Recibido: 8 de mayo de 2020. Aceptado: 3 de julio de 2020.

Este trabajo se ha desarrollado durante mi estancia en el Instituto de Estudios Medievales y Renacentistas y de Humanidades Digitales de la Universidad de Salamanca en el marco del proyecto de investigación «Teoría de la lectura y hermenéutica literaria en la Ilustración (1750-1808): edición y estudio de fuentes documentales y literarias» (referencia FFI2016-80168-P), concedido por el Ministerio de Economía, Industria y Competitividad y dirigido por la Dra. María José Rodríguez Sánchez de León. Agradezco a Dña. Verónica García Martín su colaboración en la realización de este artículo. 


\section{En torno a la definición y orígenes de la tonadilla escénica}

Uno de los mayores estudiosos de la tonadilla escénica fue José Subirá, y sus publicaciones sobre este género musical del siglo XVIII que también tiene mucha influencia en la literatura por sus letras constituyen, aun habiendo visto la luz a comienzos del siglo xx, el punto de partida ineludible para cualquier aproximación a esta peculiar muestra literaria. Subirá define las tonadillas escénicas como

[...] aquellas producciones literario-musicales que comenzaron a fructificar hacia 1750, y durante medio siglo florecieron esplendorosamente, para caer bien pronto en olvido profundo, caracterizándose todas ellas por ocupar buena parte o la totalidad de los intermedios teatrales en las representaciones de comedias y por tener vida propia e independiente, a la vez que una extensión relativamente considerable, debido a la diversidad de piezas musicales que integraban la obra ${ }^{1}$.

Las aportaciones de Subirá ${ }^{2}$ que en gran medida sentaron cátedra durante décadas, han sido superadas por la crítica más reciente ${ }^{3}$. La definición que se ha reproducido pretende ser muy general, y precisamente por ello únicamente hace alusión a su carácter literario y musical, a la época en la que se desarrollan y a su ubicación en los espectáculos teatrales, lo que la convierte en imprecisa. Subirá mejora notablemente la definición a lo largo de su propio trabajo, tratando las principales características y los temas que se incluyen en las tonadillas.

Huertas Vázquez explica que «los principales géneros menores-intermedios o epílogos literario-musicales eran la jácara entremesada, los entremeses

1 José Subirá Puig, La tonadilla escénica, t. I, Concepto, fuentes y juicios. Origen e historia, Madrid, Tipografía de Archivos, 1928, pág. 13.

2 El contexto de la magna obra de Subirá, sus principales aportaciones y algunas de las críticas que recibió han sido abordadas en María CÁCERES-PiÑUEL, «José Subirá y la recuperación de la tonadilla escénica (1928-1932)», Artigrama, 26 (2011), págs. 837-856.

3 Pessarrodona resume los principales avances en las investigaciones sobre el género que últimamente han desarrollado ella misma y las investigadoras Elisabeth Le Guin y Rebecca Haidt en Aurèlia PesSarrodona PÉrez, «La tonadilla hoy: tres visiones desde el extranjero», Matèria, 9 (2015), págs. 179-186. 
cantados, los bailes entremesados, y las mojigangas y fines de fiesta» ${ }^{4}$ y que en ellos está el origen de la tonadilla escénica; sin embargo, no parece interesarle demasiado cuáles son los antecedentes literarios del género y sí ahonda en su éxito. Sí nos parece muy relevante, desde el punto de vista histórico-literario, encontrar una filiación de la tonadilla escénica que permita obtener una hermenéutica clara sobre la evolución del teatro breve español ${ }^{5}$. Por otro lado, no debe perderse de vista que el éxito de la tonadilla escénica viene motivado, en parte, por su reacción ante la profusión de formas musicales extranjeras, como sostiene Romero Ferrer ${ }^{6}$.

No debe confundirse la tonadilla musical con la tonadilla escénica. Se llamaba tonadilla a la música que acompañaba a ciertas canciones en las representaciones dramáticas. La tonadilla escénica es, verdaderamente, un género de teatro musical cuyos orígenes hay que rastrearlos en ese teatro breve de los Siglos de Oro; concretamente, tal y como explican Buezo y Plaza ${ }^{7}$, la tonadilla escénica está emparentada con la jácara, y podríamos afirmar con estas investigadoras (solo con el fin de acercarnos aún más a la determinación definitiva de los orígenes de la tonadilla escénica, particular harto complejo y no exento de dudas) que este género musical podría concebirse en un primer estadio como la refundición de la música y el canto de las jácaras. Cotarelo y Mori ${ }^{8}$ es de la opinión de que lo más artístico y bello de las jácaras continuaron en las tonadillas y que, a finales del siglo XVII, coexistieron unas jácaras epigonales y unas tonadillas incipientes. Doménech ${ }^{9}$ apunta que la tonadilla también tiene puntos de concomitancia con el baile y la mojiganga, asumiendo una posibilidad de origen alrededor de las partes cantadas de los sainetes. Resulta de interés el análisis que hace Pérez Mora sobre la vinculación de las tonadillas con los villancicos

4 Eduardo Huertas Vázquez, Teatro musical español en el Madrid ilustrado, Madrid, Avapiés, 1989, pág. 54.

5 Para una bibliografía general sobre el teatro breve véanse Agustín de la Granja LóPEz y María Luisa Lовато LóPEZ, Bibliografía descriptiva del teatro breve español (Siglos XV-XX), Madrid / Frankfurt am Main, Iberoamericana / Vervuert, 1999 y Javier Huerta Calvo (dir.), Historia del teatro breve en España, Madrid / Frankfurt am Main: Iberoamericana / Vervuert, 2008.

6 Alberto Romero Ferrer, «Un ataque a la estética de la razón. La crítica ilustrada frente a la tonadilla escénica: Jovellanos, Iriarte y Leandro Fernández de Moratín», Cuadernos de Ilustración y Romanticismo, 1 (1991), págs. 105-128; pág. 108.

Catalina Buezo Canalejo y Nuria Plaza Carrero, «Tipología de las formas breves», en Javier Huerta Calvo (dir.), Historia del teatro breve en España, Madrid / Frankfurt am Main, Iberoamericana / Vervuert, 2008, págs. 63-119; pág. 98.

8 Emilio Cotarelo y Mori, Colección de entremeses, loas, bailes, jácaras y mojigangas desde fines del siglo XVI a mediados del XVIII, t. I, ed. de José Luis Suárez García y Abraham Madroñal Durán, Granada, Universidad de Granada, 2000, pág. CCLXXXVII.

9 Fernando Doménech Rico (ed.), Antología del teatro breve español del siglo XVIII, Madrid, Biblioteca Nueva, 1997, pág. 38. 
a partir de los metros y formas estróficas (así como recursos de composición) de las diferentes partes de este teatro breve musical ${ }^{10}$.

No debemos olvidar que las tonadillas vinieron a sustituir a los entremeses — cuando ya el género se consolidaba- en los intermedios de las representaciones dramáticas mayores. Palacios ${ }^{11}$ considera que contribuían a animar la seriedad de las piezas mayores.

González Troyano $^{12}$ ya adelantó la necesidad de afrontar el estudio de la tonadilla escénica desde el punto de vista literario, pues el aspecto musical está más avanzado. Este investigador sostiene que, literariamente, la tonadilla comulga con ciertas características del sainete, aunque también existirían otros rasgos que la diferenciarían de él y que permitirían entender el éxito de la tonadilla como pieza exenta durante la segunda mitad del siglo XVIII. Sala Valldaura, por su parte, cree que

[...] la tonadilla escénica y el sainete se emparentan con la «familia numerosa» del teatro breve áureo, con el entremés, el entremés cantado, el baile (por ejemplo, el pastoril), el intermedio lírico, la jácara (entremesada o no), el villancico teatral, etc., sin que por ello quepa negar algunas diferencias en sus respectivas raíces folclóricas ${ }^{13}$.

La parquedad en los estudios puramente literarios de los textos de las tonadillas escénicas se manifiesta en el hecho de que desconozcamos el nombre de muchos autores de los textos, como ya señaló García Garrosa ${ }^{14}$, sustentado esto en un anonimato muy probablemente deliberado ante el carácter volátil, menor y poco proclive al desarrollo de verdaderas técnicas poéticas de las letras tonadilleras.

10 Rosario Pérez Mora, «El villancico de tonadilla, un digno antecedente de la Tonadilla Escénica», en Joaquín Álvarez Barrientos y Begoña Lolo Herranz (eds.), Teatro y música en España: los géneros breves en la segunda mitad del siglo XVIII, Madrid, Consejo Superior de Investigaciones Científicas y Universidad Autónoma de Madrid, 2008, págs. 89-104.

11 Emilio Palacios Fernández, El teatro popular español del siglo xVIII, Lleida, Milenio, 1998, pág. 133.

12 Alberto GonzÁlez Troyano, «En torno a la tonadilla escénica», en Joaquín Álvarez Barrientos y José Checa Beltrán (eds.), El siglo que llaman ilustrado. Homenaje a Francisco Aguilar Piñal, Madrid, Consejo Superior de Investigaciones Científicas, 1996, págs. 487-491; pág. 488.

13 Josep Maria Sala Valldaura, «Pablo Esteve, sainetero: "Despedido quien despide" y "El calderero y la vecindad”», en Joaquín Álvarez Barrientos y Begoña Lolo Herranz (eds.), Teatro y música en España: los géneros breves en la segunda mitad del siglo XVIII, Madrid, Consejo Superior de Investigaciones Científicas y Universidad Autónoma de Madrid, 2008, págs. 325-350; pág. 325.

14 María Jesús García Garrosa, «Joaquina Comella, autora desconocida de los libretos para siete tonadillas de Blas de Laserna», Cuadernos dieciochistas, 16 (2015), págs. 125-163; págs. 126-127. 
En cualquier caso, como puede entreverse, se trata de un género dieciochesco derivado del Barroco. Romero Ferrer ${ }^{15}$ apunta que «la mirada oficial de la Ilustración ve en el sainete y sus aledaños dramáticos — la tonadilla escénica, el baile dramático, la parodia dramática — unas formas teatrales de ascendencia barroca». Pero que la tonadilla sea un género derivado del Barroco no es un hecho extraño, pues tanto el sainete (género de teatro breve que evoluciona a partir del entremés) como la comedia de espectáculo que estudió Cañas Muri$11 o^{16}$ fueron, también, géneros surgidos en el siglo XVIII a partir de antecedentes literarios auriseculares, presentes en el panorama teatral del Setecientos como consecuencia del éxito del que aún gozaban entre el público popular. Andioc ${ }^{17}$ recuerda que la existencia de este género lleva a pensar en los gustos musicales del auditorio y en la contribución de la tonadilla a la preservación de ese tipo de música.

Las tonadillas escénicas incluyen temas del gusto del público que acudía al teatro popular y que servían, fundamentalmente, para divertirlo. Sin embargo, las elites ilustradas no se sintieron representadas con este género ${ }^{18}$, lo que fomentaba esa brecha que existía entre los deseos de la intelectualidad y los intereses del vulgo. Pero estos son los que, en definitiva, motivan que los contenidos fueran cercanos a ellos y mostraran las realidades del pueblo, las relaciones amorosas y otras formas de interrelación social o el costumbrismo como mecanismo para mostrar los rasgos más tradicionales y prototípicos del entramado personal y social, muy cerca de lo que Escobar denominó mímesis costumbrista, que definió como la «forma mimética de lo local y circunstancial mediante la observación minuciosa de rasgos y detalles de ambiente y de comportamiento colectivo diferenciadores de una fisonomía social particularizada y en analogía con la verdad histórica» ${ }^{19}$. Por su parte, Labrador López de Azcona asumió sin reparos que las tonadillas mostraban el costumbrismo del Madrid de la época ${ }^{20}$, lugar donde surgió la mayoría de las obras del género. Siguiendo esa misma línea, convendremos en que la presencia de personajes y contenidos más o menos

15 Alberto Romero Ferrer, "Ya no se va al teatro por la comedia, sino por sainetes y tonadillas": Nifo frente al sainete en la batalla teatral de la Ilustración», Anuario de Estudios Filológicos, XXXVI (2013), págs. 123-145; pág. 128.

16 Jesús Cañas Murillo, «Apostillas a una historia del teatro español del siglo XVIII», Anuario de Estudios Filológicos, XIII (1990), págs. 53-63.

17 René Andioc, Teatro y Sociedad en el Madrid del siglo XVIII, Madrid, Castalia, 1987, pág. 55.

18 Alberto Romero Ferrer, «Un ataque a la estética de la razón», pág. 116.

19 José Escobar Arronis, «La mímesis costumbrista», Romance Quarterly, 35, 3 (1988), págs. 261270; pág. 262.

20 Germán Labrador LóPez dE Azcona, «El costumbrismo. Una mirada desde el género», Scherzo, XVIII, 176 (2003), págs. 118-121; pág. 118. 
estereotipados —incluso procedentes del extranjero- que muestran sus usos y tradiciones coadyuvan a la mejora del perfil costumbrista de las tonadillas. Palacios también ahonda en la idea de que las tonadillas muestran las vivencias y los comportamientos del pueblo ${ }^{21}$.

No era infrecuente encontrar, además, cierta crítica social a determinados procesos y a alguna caracterización tópica de diferentes personas y grupos. Por eso aparecerán en las tonadillas la «xenofobia antifrancesa, la afirmación nacional, las nuevas formas de conducta (majismo) y de relaciones amorosas» ${ }^{22}$. Lolo considera que las tonadillas reflejan comportamientos sociales aun vislumbrándose una aparente simplicidad ${ }^{23}$. Como se analiza más adelante, El sistema de los preocupados de Blas de Laserna, obra que se estudia en estas páginas, no es ajena a esas críticas, muy especialmente a la primera de ellas: la moda afrancesada ${ }^{24}$. En muchos casos se trataba de obras que criticaban la asunción de gustos propios de los extranjeros, como sostiene González Troyano ${ }^{25}$.

Leza $\mathrm{Cruz}^{26}$ introduce dos rasgos distintivos de las tonadillas en su definición: su carácter popular y su comicidad. Además, Albiac Blanco ${ }^{27}$, más recientemente, anota los asuntos sobre los que tratan estas composiciones. La relevancia de la puesta en escena, de la interacción con el público y de la música y la danza — junto con el limitado cultivo de una perfecta poética literaria- han sido apreciadas, entre otros, por Labrador López de Azcona ${ }^{28}$.

En cuanto a su forma, Subirá ${ }^{29}$ advierte que «en las tonadillas a solo se destaca la nota satírica, utilizándose en lo literario la forma estrófica con letrilla y en lo musical la pieza denominada "copla"».

21 Emilio Palacios Fernández, «La teoría dramática», en Javier Huerta Calvo (dir.), Historia del teatro breve en España, Madrid / Frankfurt am Main, Iberoamericana / Vervuert, 2008, págs. 547-638; págs. 575-576.

22 José Máximo Leza Cruz, «El teatro musical», en Javier Huerta Calvo (dir.), Historia del teatro español, vol. II, Del siglo XVIII a la época actual, Madrid, Gredos, 2003, págs. 1687-1713; pág. 1706.

23 Begoña Lolo Herranz, «Itinerarios musicales en la tonadilla escénica», en Paisajes sonoros en el Madrid del s. XVIII. La Tonadilla Escénica, Madrid, Museo de San Isidro / Excmo. Ayuntamiento de Madrid, 2003, págs. 15-30; pág. 15.

24 Algunos caracteres atribuidos a lo francés en el siglo XVIII y presentes en las tonadillas son tratados en Aurèlia Pessarrodona Pérez, «Representaciones musicales de lo francés en tonadillas dieciochescas», Mélanges de la Casa de Velázquez, 46, 1 (2016), págs. 167-193. Especial interés para este trabajo tienen las aportaciones a propósito de la afectación y la exageración de los sentimientos.

25 González Troyano, «En torno a la tonadilla escénica», pág. 489.

26 Leza Cruz, «El teatro musical», págs. 1706-1707.

27 María Dolores Albiac Blanco, «Teatro musical», en José Carlos Mainer (dir.), Historia de la literatura Española, t. 4, Razón y sentimiento (1692-1800), Barcelona, Crítica, 2011, págs. 516-522; págs. $520-521$.

28 Germán Labrador LóPEz de Azcona, «Una mirada sobre la tonadilla: música, texto e intérpretes al servicio de un nuevo ideal escénico", en Paisajes sonoros en el Madrid del s. XVIII. La Tonadilla Escénica, Madrid, Museo de San Isidro / Excmo. Ayuntamiento de Madrid, 2003, págs. 39-47; págs. 43-44.

29 Subirá Puig, La tonadilla escénica, t. I, pág. 158. 
Es también relevante la periodización que Subira ${ }^{30}$ realiza de la tonadilla escénica, dividiendo su trayectoria como género en cinco etapas, las cuales denomina de la siguiente forma: «aparición y albores» (1751-1757), «crecimiento y juventud» (1757-1770), «madurez y apogeo» (1771-1790), «hipertrofia y decrepitud» (1791-1810) y «ocaso y olvido» (1811-1850). Algunos de los términos que propone el musicólogo catalán no parecen ajustarse a las convenciones que suelen emplearse en historia de la literatura, pero no es objeto de este trabajo matizar esta clasificación, que podría revisarse y ha sido revisada a la luz de estudios más recientes sobre la tonadilla escénica ${ }^{31}$; y no solo en la nomenclatura, sino más bien atendiendo a criterios más filológicos como, por ejemplo, la consolidación de rasgos de una poética de la tonadilla o la repetición de estructuras. Ciertamente, la clasificación de Subirá atiende a criterios evolutivos demasiado estancos que no responden a las necesidades de las propias características compositivas de las obras de este género. Begoña Lolo ${ }^{32}$ ya advirtió, por ejemplo, que las características de las tonadillas de Laserna adscribirían las composiciones a una etapa diferente a la que le correspondería por cronología; es, por tanto, una periodización que necesita ser revisada con criterios filológicos.

Para el período de madurez, que es al que pertenecería la tonadilla que se estudia en este artículo, Subirá ${ }^{33}$ propone, como rasgos generales, la voluntad por importar la ópera italiana y el creciente descuido de las tonadillas. Además, califica a Leandro Fernández de Moratín como uno de los mayores críticos hacia este género, tal y como expresó el autor de El sí de las niñas en La derrota de los pedantes ${ }^{34}$.

Pero el éxito de la tonadilla escénica llevó a publicar escritos sobre el género ya en el siglo XVIII, como Origen y progresos de las tonadillas que se cantan en los coliseos de esta corte, publicado en el Memorial Literario, Instructivo y Curioso de la Corte de Madrid en septiembre de 1787, que señalaba que «en el año de 1757 D. Luis Misón abrió nuevo camino a las canciones del teatro y, para una función de Corpus, presentó una nueva composición a dúo, que fue el

30 Subirá Puig, La tonadilla escénica, t. I, pág. 158.

31 Aun reconociendo la valía de la clasificación de Subirá, Le Guin afronta una revisión en Elisabeth LE GuIN, «Hacia una revalorización de la tonadilla tardía», en Joaquín Álvarez Barrientos y Begoña Lolo Herranz (eds.), Teatro y música en España: los géneros breves en la segunda mitad del siglo XVIII, Madrid, Consejo Superior de Investigaciones Científicas y Universidad Autónoma de Madrid, 2008, págs. 183-223.

32 Begoña Lolo Herranz, «La tonadilla escénica, ese género maldito», Revista de Musicología, XXV, 2 (2002), págs. 439-469; pág. 465.

33 Subirá Puig, La tonadilla escénica, t. I, pág. 194.

34 Subirá Puig, La tonadilla escénica, t. I, pág. 200. 
modelo o principio de las que ahora se llaman tonadillas» ${ }^{35}$. Le Guin ${ }^{36}$ entiende que «this essay represents the first attempt at a history of genre».

\section{Blas de Laserna}

El 4 de febrero de 1751 nació en Corella (Navarra) Blas de Laserna y de Nieva, de cuyos primeros estudios carecemos de datos ${ }^{37}$. Sabemos que a los diecinueve años se trasladó a Madrid, donde culminaría su formación musical y ofrecería algunos conciertos para ganarse la vida. Conoce al compositor Vicente Adán y en 1773 se casa con su hermana, María Teresa Adán, mayor que Laserna. Tuvieron tres hijos: Micaela, Juan Paulino y Eugenio.

Gómez $^{38}$ indica que las primeras tonadillas que el músico compuso datan de 1774. Pertenece, por esos años, a la compañía de Juan Ponce, a la de Manuel Martínez y a la de Eusebio Rivera. También frecuenta casas nobiliarias para interpretar algunas piezas, como la de doña María Josefa de la Soledad AlfonsoPimentel y Téllez-Girón, XII Duquesa de Benavente.

En la temporada teatral 1785-1786 Laserna aparece como compositor del teatro de la Cruz de Madrid y, en la siguiente, del teatro del Príncipe. Años más tarde creó una escuela de cantar tonadillas en la capital, particular que había solicitado en $1790^{39}$.

Enviudó Laserna en 1795, y al año siguiente volvió a contraer matrimonio, ahora con María Pulpillo y Barco, artista retirada que falleció en 1809. Laserna no tuvo hijos de su segundo matrimonio. Sus últimos años los pasó nuestro compositor vendiendo algunas copias de obras y ofreciendo algunos conciertos o recitales; siempre se quejó el navarro de la escasez de sus salarios y de la cantidad de obras que tenía que componer, como recoge Herrera Navarro ${ }^{40}$. Falleció el 8 de agosto de 1816.

35 Origen y progresos de las tonadillas que se cantan en los coliseos de esta corte, Memorial Literario, Instructivo y Curioso de la Corte de Madrid, XLV, 1787, págs. 168-174; págs. 170-171.

36 Elisabeth Le Guin, The Tonadilla in Performance. Lyric Comedy in Enlightenment Spain, Berkeley, University of California Press, 2014, pág. 2.

37 Es fundamental la siguiente biografía, que aporta numerosos e interesantes datos sobre el músico: José Luis de Arrese Magra, Eduardo Aunós Pérez y Julio Gómez Aparicio, El músico Blas de Laserna, Corella, Biblioteca de Corellanos Ilustres, 1952.

38 Julio Gómez Aparicio, «Don Blas de Laserna. Un capítulo de la historia del teatro lírico español visto en la vida del último tonadillero», Revista de Biblioteca, Archivo y Museo, VII (1925), págs. 406-430; pág. 415.

39 Julio Gómez Aparicio, «Don Blas de Laserna. Un capítulo de la historia del teatro lírico español visto en la vida del último tonadillero», Revista de Biblioteca, Archivo y Museo, IX (1926), págs. 88-104; págs. 95-96.

40 Jerónimo Herrera Navarro, Catálogo de autores teatrales del siglo xVII, Madrid, Fundación Universitaria Española, 1993, pág. 257. 
Subirá ${ }^{41}$ indica que, en la etapa de madurez de la tonadilla escénica, Blas de Laserna es uno de sus cuatro grandes compositores junto con Pablo Esteve, Antonio Rosales y Jacinto Valledor. Como apunta Subirá, «Laserna presenció la juventud de la tonadilla, su plenitud y su ocaso, contribuyendo él mismo, en las diversas fases de esa evolución, a imprimirle los rumbos que sucesivamente fue tomando» ${ }^{42}$. De hecho, la importancia de su producción trascendió la España peninsular y fue el autor más prolífico de los que se representaron en el Coliseo de México, por ejemplo, en 1792, como apunta Vera García ${ }^{43}$.

Conservamos manuscritos de sus piezas en la Biblioteca Nacional de España, en la Biblioteca Histórica Municipal de Madrid y en la Biblioteca del Real Conservatorio Superior de Música de Madrid, entre otras. Sus tonadillas son, sin duda, lo mejor y lo más abundante de su producción. Escribió cientos de tonadillas escénicas (algunas con libreto) a solo, a dúo, a tres, a cuatro, a cinco, a seis, a siete y generales, incluso con coro, datadas la mayoría de ellas entre 1779 y 1790, esto según Gómez ${ }^{44}$. Pero además dio a la luz música para comedias como El perseguido, para entremeses como El reto y los títeres, para sainetes como El celoso burlado y algunas obras mayores, como la opereta La gitanilla por amor, la zarzuela con libreto El premio de la constancia o la ópera Fígaro. Gómez ${ }^{45}$ ofrece un interesante catálogo alfabético de hasta 868 obras de Blas de Laserna, ampliable con los fondos de otras bibliotecas y archivos.

\section{El sistema de los preocupados: tonadilla escénica costumbrista}

El sistema de los preocupados (o simplemente Los preocupados) es una tonadilla escénica en siete movimientos compuesta por el navarro Blas de Laserna en 1786. La pieza fue escenificada para la comedia El hechizado por fuerza de Antonio de Zamora por la compañía teatral de Eusebio Rivera (a la que perteneció Laserna como compositor) en sus representaciones en el coliseo o teatro

41 José Subirá Puig, La tonadilla escénica. Sus obras y sus autores, Barcelona / Buenos Aires, Labor, 1933, pág. 127.

${ }_{42}$ José Subirá Puig, La tonadilla escénica, t. III, Transcripciones musicales y libretos. Noticias biográficas y apéndices, Madrid, Tipografía de Archivos, 1930, pág. 77.

43 Rey Fernando Vera García, «Primer acercamiento al estudio de la tonadilla escénica en Nuevo México durante el siglo XvIII: Edición de la letra de la tonadilla a solo: Ya tienes México Grande, sobre la crítica que se hace de las cosas de teatro", Revista de literaturas populares, XVIII, 1, 2018, págs. 158-190; pág. 170.

44 Julio Gómez Aparicio, «Don Blas de Laserna. Un capítulo de la historia del teatro lírico español visto en la vida del último tonadillero», Revista de Biblioteca, Archivo y Museo, VIII (1925), págs. 531-548; pág. 538 .

45 Julio Gómez Aparicio, «Don Blas de Laserna. Un capítulo de la historia del teatro lírico español visto en la vida del último tonadillero», Revista de Biblioteca, Archivo y Museo, X (1926), págs. 222-240. 
del Príncipe de Madrid, pasando más tarde a América. La letra fue interpretada por la soprano lírica Joaquina Arteaga, una famosa cantante y actriz de finales del XVIII que ingresó en la compañía de Rivera en la temporada teatral 1783$1784^{46}$ y se retiró en 1807, momento en el que circuló una obrita, como recogen Díaz de Escovar y Lasso de la Vega ${ }^{47}$, en la que se leía «Jubilamos a la Joaquina Arteaga en consideración a lo que ha trabajado corporalmente, que no ha sido poco, como lo sabe el público».

Dicho lo anterior, procede atender a continuación a tres cuestiones fundamentales de El sistema de los preocupados: la referencia de los ejemplares localizados que sirven para la edición infra y su aparato crítico, la clasificación de la tonadilla y el análisis de su estructura y los aspectos temáticos que aborda dentro de la crítica costumbrista a la preocupación afrancesada.

Conservamos cuatro testimonios de El sistema de los preocupados, dos guiones manuscritos con libreto y dos textos sin música, uno manuscrito y otro impreso.

El primero de ellos es el guion con texto que se conserva en la Biblioteca Histórica Municipal de Madrid con la signatura Mus 73-18, que procede del Archivo de música de los teatros de la Cruz, Príncipe y Caños del Peral. Esta partitura comprende, tras una página con los datos de identificación de la pieza (el género, su título, su compositor y el año), el guion completo de la obra con instrumentos y voz en diecinueve páginas de veintitrés por treinta y un centímetros y las partichelas de varios instrumentos: cuatro páginas para violín primero, cuatro para violín primo [sic], dos juegos de cuatro para violín segundo, tres para oboe primero, tres para oboe segundo, tres para trompa primera, tres para trompa segunda y cuatro para contrabajo. Las partichelas de los violines y del contrabajo van precedidas de sendas portadillas que indican el título de la obra, su género (tonadilla a solo) y el instrumento al que pertenece esa partichela. En el aparato crítico que acompaña a la edición del texto este ejemplar será denominado $H$ como referencia a su conservación en la Biblioteca Histórica Municipal de Madrid.

El segundo testimonio manejado, también guion con texto, consta de veintidós páginas de treinta y cinco centímetros y está custodiado en la Biblioteca Nacional de España con la signatura MC/3051/12 $2^{48}$. Procedente de la Biblioteca Francisco Asenjo Barbieri (músico, profesor y compositor de zarzuelas) y en ella

46 Emilio Cotarelo y Mori, Actrices españolas en el siglo XVIII, Madrid, Asociación de Directores de Escena de España, 2007, pág. 228.

47 Narciso Díaz de Escovar y Francisco de Paula Lasso de la Vega, Historia del teatro español, t. I, Barcelona, Montaner y Simón, 1924; pág. 352.

48 Blas de LASERna, El sistema de los preocupados, s. 1., s. e., 1786, sign. MC/3051/12 de la Biblioteca Nacional de España. 
intervienen dos violines y dos trompas, además de la voz. A la escritura de la música le preceden el año de la tonadilla, su título, el género al que pertenece la obra (tonadilla a solo), su compositor, el nombre del director de la compañía teatral que la representó y el de la soprano lírica que la interpretó. Este guion es más parco en instrumentación que el anterior, el cual incluye, además de dos voces más de violines, dos de oboes y una de contrabajo; sin embargo, las trompas son exclusivas de esta segunda partitura. Denominaremos $N 1$ a este ejemplar en alusión al primero de los dos testimonios que pertenece a la Biblioteca Nacional de España.

Existe un manuscrito en la Biblioteca Nacional de España con la signatura MSS/14065/4 que contiene el texto sin música y que también procede de la Biblioteca Barbieri. Dicho texto se recoge en cinco páginas, y en la primera se incluyen los siguientes datos: el género de la pieza, su título, la compañía que representó esta tonadilla, su compositor, la fecha, la soprano que cantó el texto y el nombre del oficial de la Vicaría Eclesiástica de Madrid, entidad que otorgó la licencia. Las siguientes cuatro páginas contienen varias licencias, censuras y anotaciones que se incluyen en la edición del texto; aparecen varias manos en esta segunda parte del manuscrito, según se trate de las distintas aprobaciones. Todo el testimonio está dentro de una carpetilla en cuya portada aparece el título de la tonadilla en una mano diferente y posterior a las del resto del manuscrito. Es el ejemplar $N 2$ del aparato crítico como segundo testimonio conservado en la Biblioteca Nacional de España.

Finalmente, el texto fue recogido por el Memorial Literario, Instructivo y $\mathrm{Cu}$ rioso de la Corte de Madrid entre las páginas 546 y 549 de su número XXVIII, correspondiente al mes de abril de 1786. Fue impreso en la Imprenta Real de Madrid $^{49}$. Comienza el texto indicando, en un breve párrafo, el género al que pertenece la tonadilla, su título, la soprano que la interpretó, el lugar en el que se representó y la comedia a la que acompañó. Por haberse publicado en el Memorial Literario, este testimonio se denomina $M L$ en el apartado crítico de la edición de El sistema de los preocupados y es el único de los cuatro que contiene signos de puntuación, que adaptamos a las convenciones actuales.

La clasificación de las tonadillas escénicas se organiza, en primer lugar, en función del número de personajes que interviene en ellas. Ya desde su contemporaneidad se dividían en tonadillas a solo o monológicas (si solo interviene uno), a dúo, a tres, a cuatro, a cinco, a seis, a siete, etc., reservando el marbete de tonadillas generales para aquellas en las que participan varios agonistas. El

49 [Blas de LaSERNa], El sistema de los preocupados, en Memorial Literario, Instructivo y Curioso de la Corte de Madrid, XXVIII (1786), págs. 546-549. 
sistema de los preocupados de Laserna es una tonadilla a solo, pues se trata del soliloquio de un personaje que presenta una situación al público y lo interpela.

A partir de ahí, Subirá, en función del argumento o de la intencionalidad de las tonadillas a solo, las clasifica en «satíricas, refraneras, narrativas, metafóricas, simbólicas, psicológicas y autobiográficas $»^{50}$. La tonadilla satírica, grupo al que pertenece El sistema de los preocupados, responde a la siguiente caracterización, aportada por Subirá:

Las tonadillas satíricas se distinguían por su aguda mordacidad. Recaían frecuentemente contra determinadas personas o colectividades, que no podían por menos de sentirse ofendidas, aunque se omitiera su nombre; y las alusiones solían ser tan directas, que también los auditorios comprendían a quiénes se dirigían en cada caso concreto los dardos de la sátira. [...] Enlazaban una serie de «coplas»o estrofas, cada una de las cuales condensaba el asunto de un sainete, convirtiendo allí en señalamiento de vicios, defectos o ridiculeces comunes a parte de la humanidad lo que los sainetes exponían de modo sucinto, como caso concreto de igual índole con personajes y acción escénica. Rematose cada grupo de tres o cuatro coplas, durante largo tiempo, con unas «boleras» que hacía observaciones sobre los casos expuestos, o manifestaban que a nadie se quería zaherir directamente, o aconsejaba que se rascase todo aquel a quien la misma le había picado ${ }^{51}$.

Las tonadillas escénicas hasta, aproximadamente, la década de 1770 constaban generalmente de una estructura tripartita: entable, coplas y seguidillas. Lolo sostiene que, a partir de ese momento, se convierten «en una obra en un acto que se organizaba en una sucesión de números sin delimitar, mixtura de elementos a modo de amalgama o acumulación de pequeñas formas musicales ${ }^{52}$, ello provocado por la mayor extensión de las tonadillas, cuyos compositores se veían obligados a tomar materiales de otras composiciones más o menos de repertorio para incluirlas en la propia tonadilla. Le Guin explica con algunos ejemplos el proceso de refundición de tonadillas con textos previos ${ }^{53}$, hecho que, en nuestra opinión, muestra el vínculo entre el género y el público y enriquece el proceso de transmisión de los textos, de tal manera que «from this palimpsestic chaos we can draw the reasonable conclusion that the number of episodes probably varied from performance to performance, according to the

50 José Subirá Puig, La tonadilla escénica, t. II, Morfología literaria. Morfología musical, Madrid, Tipografía de Archivos, 1929, pág. 100.

51 Subirá Puig, La tonadilla escénica, t. II, pág. 101.

52 Lolo Herranz, «Itinerarios musicales en la tonadilla escénica», pág. 20.

53 Le Guin, The Tonadilla in Performance. Lyric Comedy in Enlightenment Spain, pág. 217 y ss. 
availability, talents, and tastes of the players ${ }^{54}$. Siguiendo las posturas de Lolo, Pessarrodona y Le Guin, esto nos aleja de considerar las tonadillas posteriores a 1790 como pertenecientes a una etapa de «hipertrofia y decrepitud», señalada así por Subirá.

Al analizar la estructura de la tonadilla El sistema de los preocupados podemos asumir la clásica estructura tripartita. La primera parte la forma una introducción cuyo fragmento más relevante se denomina entable; consiste en la exposición preventiva del tema sobre el que se va a tratar en la pieza, lo cual se manifiesta en la tonadilla laserniana entre los versos 1 y 32 . Siguen al entable unos versos que ponen fin a la introducción y que, en ocasiones, reciben el nombre de coleta, tal y como recoge Subirá ${ }^{55}$. En El sistema de los preocupados estos últimos versos de la introducción van del 33 al 42, donde los cuatro primeros se recitaban y el resto se cantaba.

La segunda parte son las coplas, y constituyen el elemento nuclear de las tonadillas escénicas. En ellas se concentra la narración de los contenidos que trata de representar la tonadilla. El sistema de los preocupados concentra sus coplas en dos series entre los versos 43 y 58 y 66 y 81 , ambas con cuatro cuartetas romanceadas (toda la tonadilla mantiene rimas asonantes en los versos pares). Los dos grupos de coplas son rematados por unas boleras entre los versos 59 y 65 y 82 y 90. Según explica Subirá,

[...] las boleras juzgan, comentan y resumen la materia de las coplas; hacen reflexiones, dan consejos para que se enmienden los vicios, concretan censuras, insinúan moralejas, indican remedios, muestran instrucciones, señalan peligros, aclaran intenciones, reclaman disculpas por el atrevimiento, piden su conformidad a las personas que podrían considerarse aludidas, justifican la sátira, aconsejan o disuaden ${ }^{56}$.

Tratan, en definitiva, de extractar y sintetizar el tema previamente desarrollado en las coplas, parte central de la tonadilla escénica.

La última sección de esa estructura tripartita la constituyen las seguidillas, que vienen a constituir una suerte de epílogo de la pieza tan libre que puede respetar la línea argumental de la tonadilla para condensarla o no o introducir brevemente algún otro asunto tangencial. El sistema de los preocupados recoge sus seguidillas entre los versos 91 y 106, cuando finaliza la composición.

54 Le Guin, The Tonadilla in Performance. Lyric Comedy in Enlightenment Spain, pág. 220.

55 Subirá Puig, La tonadilla escénica, t. II, pág. 192.

56 Subirá Puig, La tonadilla escénica, t. II, pág. 206. 
Desde el punto de vista temático de esta composición procede recordar que el gusto francés se impone en la Europa del siglo XVIII y, concretamente, en España, donde incluso la llegada de la nueva centuria coincidió con el ascenso al trono de una nueva dinastía, los Borbones, de origen francés. Evidentemente esto supuso una extensión de lo afrancesado en la corte del rey Felipe $V$ y de sus sucesores, y como la corte se entiende como modelo para el resto de la sociedad (amén de que a ella suelen pertenecer los legisladores), la sociedad española en su conjunto se vio orientada hacia el estilo francés. Sin embargo, no debe olvidarse que ese afrancesamiento es, sobre todo, una tendencia elitista y propia de las altas clases sociales y culturales.

Son las tonadillas, junto con los sainetes, las composiciones de teatro breve que mejor tratan el costumbrismo. El sistema de los preocupados de Blas de Laserna se dedica a describir una costumbre del Madrid de la época: la preocupación. Los preocupados son los que se quedan con la primera impresión de las cosas y solo se guían por las apariencias; el triunfo de esas apariencias en la moda española del XVIII era precisamente lo afectado y lo francés. La tonadilla critica y satiriza la costumbre de las apariencias en la vida de la época. No es extraño encontrar tonadillas en las que se retraten comportamientos o costumbres extranjeras con el fin de criticarlas o, cuando menos, de cuestionarlas; y como no podía ser de otra forma, algunos personajes extranjeros aparecen caracterizados, por ejemplo, a través de su lengua, como en el caso de los franceses, ya estudiado por Andioc en varios lugares ${ }^{57}$.

La tonadilla adopta una posición burlesca mientras que el único personaje que interviene en ella se afana en ofrecer consejos o instrucciones a todas aquellas personas que quieran participar de la moda de la preocupación: renegar de lo patrio, fijarse en las modas extranjeras, emplear términos foráneos o teorizar sobre cualquier tema o campo del saber sin conocerlo verdaderamente y, mucho menos, habiéndolo puesto en práctica. Este es el costumbrismo de la tonadilla escénica El sistema de los preocupados de Blas de Laserna: satirizar la costumbre o moda española dieciochesca de valorar las apariencias. Un costumbrismo que hacía las delicias del público popular de la época y que permitió el éxito de este género en tan solo medio siglo de existencia real. Pasemos, a continuación, a explicar cómo se tratan estos contenidos en las diferentes partes de la tonadilla.

El entable es una introducción seria de la crítica que se va a hacer y en él se plantean algunos de los blancos que se van a abordar en la tonadilla: la pe-

57 René ANDIoc, «Les français vus par les "tonadilleros" de la fin du xvIIIe siècle», Bulletin Hispanique, 96, 2 (1994), págs. 353-375 y René ANDioc, «La figura del francés en las tonadillas de finales del siglo XVIII», en Del siglo XVIII al XIX. Estudios histórico-literarios. Zaragoza, Prensas Universitarias de Zaragoza, 2005, págs. 39-66. 
dantería y el barbarismo. Como se anota en el texto, son pedantes esos supuestos sabios que publican su cultura — que es más basta que vasta— y son bárbaros los que emplean barbarismos en el lenguaje, es decir, términos y expresiones propias del latín o de otros idiomas. Si estas particularidades confluyen en un individuo se produce su animalización, una caracterización burlesca que aparece en los versos 11 y 22 .

Las coplas están constituidas por las instrucciones que da el personaje de la tonadilla para conseguir la afectación, entre las que han de destacarse la pedantería, el conocimiento teórico de los distintos campos del conocimiento y su falta de aplicación práctica, el empleo de latinismos y galicismos para engalanar un lenguaje carente de esencia y de sustancia, el fomento de lo antiespañol y del atraso cultural de la patria como vehículo para cultivar la nula aportación de la nación al contexto científico y artístico europeo y la vida en una constante apariencia que potencie la vanidad personal de sus ejecutores.

Las boleras — que rematan las coplas_ - ponen en boca del único personaje de esta tonadilla escénica la imprecación al destinario, el español, quien debe observar las instrucciones explicitadas en las coplas si quiere convertirse en alguien relevante en su siglo. Los versos 87 y 88 vienen, además, a condensar metafóricamente la idea que se quiere transmitir acerca de la preocupación y de las apariencias: «el oropel se vende / por oro fino».

Las seguidillas finales parecen estar incluidas sin relación con el tema anterior de las apariencias ${ }^{58}$, pero sí puede establecerse un ligero correlato, especialmente con la interpretación de sus cuatro primeros versos. Las seguidillas tratan el tema de los celos, pero no se dice que los poseen los maridos de las mujeres (que serían los depositarios reales y tangibles de los amores de la dama), sino sus amantes (unos destinarios extraños o fingidos). Los celos de los amantes serían, por tanto, apariencias; siendo estas apariencias las que permiten que las seguidillas puedan vincularse temáticamente al tema de la preocupación que se desarrolla en la tonadilla.

Mención aparte merece el hecho de que también funcionan en la tonadilla el entretenimiento, la risa y la comicidad, claramente unidos al costumbrismo: el público gustaba de asistir a estas obras para evadirse y verse reflejados en ellas, así como para observar el tratamiento de sus problemas cotidianos y de las verdades sociales. Real Ramos [y Alcalde Cuevas $]^{59}$ consideran, con mucho

58 Esta plausible falta de relación parece responder a que, como se ha señalado, en la década de 1780 (fecha de composición de El sistema de los preocupados) ya estamos asistiendo a una mezcla de materiales.

59 César Real Ramos [y Luis Alcalde Cuevas], «La tonadilla: un capítulo de la historia del espectáculo del siglo XVIII", en Lina Rodríguez Cacho y Luis Alcalde Cuevas (eds.), La palabra esperada. Homenaje a César Leal Ramos, Salamanca, Ediciones Universidad de Salamanca, 2017, págs. 87-96; págs. 93-94. 
acierto, que las tonadillas son «el marco en el que clases oprimidas, majos y mujeres, triunfan en sus disputas con sus antagonistas sociales, representados por el petimetre y el usía. Se produce así una especie de catarsis social, una liberación y un triunfo que carnavalescamente se realiza en la farsa, en la fiesta». Se trataba de obras que no gustaban a las elites culturales ilustradas porque continuaban fomentando una literatura popular que debía desdeñarse, ello al amparo de las visiones neoclásicas más restrictivas ${ }^{60}$. Recuérdese, por otra parte, tal y como apunta Gómez, que

[...] la tonadilla, como obra literaria, tiene un valor principalmente histórico y documental, que puede compararse con los sainetes de D. Ramón de la Cruz. Las costumbres de la época se retratan en la tonadilla con singular crudeza, que no está velada por los afeites literarios que en otros géneros atenúan la desnuda imagen de la realidad. En tal naturalidad está su más alto mérito ${ }^{61}$.

\title{
La edición del texto
}

\author{
Blas de Laserna \\ El sistema de los preocupados \\ Tonadilla a solo
}

$1786^{62}$

[ENTABLE]

¡Qué humano discurso

no sale de quicio ${ }^{63}$

al ver cómo el vulgo

piensa con delirio!

60 Romero Ferrer, «"Ya no se va al teatro por la comedia"», pág. 132.

61 Gómez Aparicio, «Don Blas de Laserna», Revista de Biblioteca, Archivo y Museo, VIII (1925), pág. 535.

${ }_{62}$ Ton. $^{\mathrm{a}}$ a solo|El Sistema de los Preocupados | De Laserna | 1786 H 1786. | El Sistema de los Preocupados. | Tonadilla à Solo | de | Laserna | Rivera | La Cantò | Joaquina Arteaga N1 tonadilla à Solo | El sistema de los Preocupados | de Laserna | comp. ${ }^{a}$ de Rivera | 1786 | 25 Abr. 86 | la letra de | la tonadilla | la pidió la

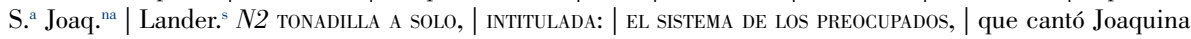
Arteaga en el Coliséo | del Príncipe en los dias que se representó | el Hechizado por fuerza. ML

${ }^{63}$ Sacar una cosa de quicio: «Violentarla o sacarla de su natural curso o estado» (Real ACAdemia Española, Diccionario de la lengua castellana. Segunda edición, Madrid, Joaquín Ibarra, 1783, s. v. 'quicio'). 
Me enternezco,

me enfurezco

al mirar

tanto pedantismo ${ }^{64}$,

tanto fanatismo,

tanto barbarismo ${ }^{65}$

en tanto ${ }^{66}$ animal.

Todas las materias

las aprecian solo

por aquel capricho

que forma su antojo.

Me enternezco,

me enfurezco

al mirar

tanto pedantismo,

tanto fanatismo,

tanto barbarismo

en tanto animal.

$\quad$ Sentado este principio ${ }^{67}$,
pintaré al punto
el sistema que siguen
en los asuntos.
El juguete ${ }^{68}$ que voy a emprender
tiene cosas que han de complacer,

64 No era infrecuente entre ciertos eruditos del siglo XVIII la costumbre de alardear de unos supuestos conocimientos con el fin de publicar a todas luces una cultura que en realidad era muy limitada. Esta pedantería fue muy criticada por los autores neoclásicos; recuérdese, a este respecto, el personaje de Don Hermógenes en la comedia de buenas costumbres titulada La comedia nueva o El café o la obra La derrota de los pedantes, ambas de Leandro Fernández de Moratín.

65 Téngase en cuenta la acepción de «vicio contra las reglas y pureza del lenguaje» que recoge la Real Academia Española s. v. 'barbarismo’ en el diccionario citado. El empleo de latinismos y otros extranjerismos (especialmente galicismos) entre los sabios pedantes fue una de las realidades más criticadas en la sociedad del momento. En esta misma tonadilla aparece este extremo ejemplificado en los versos 69 y 73 .

${ }_{66}$ La estructura versal paralelística de estos últimos versos, con el cuantificador tanto, refuerza la intención del autor.

67 El autor se refiere al final del entable.

68 Juguete: «Canción alegre y festiva» (Real Academia Española, Diccionario de la lengua castellana, s. $v$. 'juguete'), refiriéndose al fin satírico de esta pieza de teatro breve que es la tonadilla escénica. 
de suerte que el más rudo

gritará al verlo

que de los preocupados

este es el tiempo ${ }^{69}$.

[RECITADO]

En la idea, señores, que yo trato

no hiero a los sujetos que retrato,

pues la preocupación que en Madrid miro

es el blanco a quien hoy ansiosa tiro.

\section{[Cantado]}

Atiendan, que el chiste

manifestará

quién en Madrid tiene,

por la necedad,

en todas las cosas

el mejor lugar ${ }^{70}$.

\section{Coplas $^{71}$}

Todo necio que quisiere

hombre docto parecer,

de ninguna cosa entienda

y dispute en los cafés.

El pedante que de sabio

quiera tener opinión,

todo lo extranjero alabe

y hable mal de la nación ${ }^{72}$.

69 La preocupación que se entiende tan extendida en la época y que se critica en esta tonadilla consistía en esa moda afrancesada que había aterrizado en España en el siglo XvIII y que llevaba a ciertos personajes a fiarse únicamente de las apariencias de las cosas, sin prestar la menor atención a la esencia o naturaleza de ellas.

70 Qué persona ocupa, por su pedantería, un papel de relevancia en todo.

71 Esta indicación solo aparece en un testimonio: Coplas. $M L$

72 Es una época en la que había reacciones europeas muy fuertes contra España y la aportación de los españoles a la literatura y a la cultura. Precisamente renegar de los progresos de España era frecuente entre los que buscaban un gusto supuestamente refinado y a todas luces afrancesado y pedante. 
Todo charlatán que quiera

ser dentista de primor,

diga que es francés ${ }^{73}$, y cuelgue

muchas muelas del balcón.

Si una modista española

dar quiere a su tienda honor,

ponga una muestra que diga:

Tienda de Madam Culot.

[BOLERAS]

Seguid, transpirenaicos ${ }^{74}$,

esto que digo,

y seréis los Platones

de nuestro siglo.

No pongáis duda

que este siglo es el siglo

de la locura.

\section{[COPLAS]}

Todo médico que quiera

adquirir fama en Madrid,

aunque asesine en romance

diga que cura en latín ${ }^{75}$.

El peluquero que quiera

tener más estimación,

si se llama Señor Pedro,

llámese Monsieur Pierrot ${ }^{76}$.

73 Se retoma la idea de lo francés como sinónimo del buen gusto y del prestigio, tal y como también ocurrirá en el verso 58, que aporta la traducción a dicha lengua como elemento ennoblecedor, siendo culot una transliteración del vocablo francés culotte, prenda interior masculina en la época.

${ }_{74}$ Se refiere a los españoles. Se trata de una imprecación del personaje a los ciudadanos de nuestro país, situado al otro lado de los Pirineos con respecto a Francia.

75 Nótese el doble contraste entre las facultades de un médico de curar o no curar y la posibilidad de emplear latinismos o términos de lengua romance. Como se ha explicado, la preocupación era la tendencia a valorar las apariencias por encima de la esencia, y ello tiene su correlato lingüístico con el latín y las lenguas románicas: aunque no se entienda, si una persona habla en latín se le presupone sabiduría y cultura, a pesar de que no haya realizado bien su trabajo o, al menos, con éxito, como hubiera sido sanar a una persona de su enfermedad.

76 Nuevamente encontramos la traducción al francés como signo ennoblecedor del lenguaje y del quehacer de una persona, como ya había ocurrido en el verso 58. 
Todo aquel español que haga

cualquier obra con primor,

si quiere que se la aplaudan

no diga que es español ${ }^{77}$.

Todo agente que pretenda

más negocios manejar,

tenga coche con lacayo

80

y jamás diga verdad.

\section{[BoLERAS]}

Guardad, transpirenaicos,

estos preceptos,

que al que no dieren fama

darán provecho,

que en este siglo

el oropel ${ }^{78}$ se vende

por oro fino.

Y con las seguidillas

esto termino.

\section{Seguidillas $^{79}$}

Los celos de un amante

son tan impíos

que afligiendo dudosos

matan sabidos:

¡qué de congojas!

¡Qué de martirios

padece el alma

que ha de sufrirlos!

77 Como en el verso 50, hay una nueva alusión a la moda de renegar de España y de despreciar la aportación de los españoles.

78 Oropel: «Lámina de latón muy batida y adelgazada que queda como un papel». En sentido metafórico, «se dice de las cosas que son de poco valor y las hacen subir de estimación por vanidad o por engañar a otros. Y también se entiende de las oraciones llenas de palabras elegantes, pero sin sustancia» (REAL ACADemia Española, Diccionario de la lengua castellana, s. v. 'oropel'), muy cercano, como puede observarse, a la preocupación y a las apariencias.

79 Esta indicación solo aparece en dos testimonios: Seguidillas N2 Seguidillas. ML 
Desdichados amantes,

moderad vuestro ardor,

100

que estas son las delicias

que dispensa el amor;

pues como es tan travieso,

se está alegrando

del tiro ${ }^{80}$ que en las almas

105

hace más daño.

[LICENCIA Y CENSURAS ${ }^{81}$ ]

Madrid, 24 de abril de 1786.

Vista. Omitiéndose los versos los versos rayados, dese licencia.

Nos, el Dr. D. Cayetano de la Peña y Granda ${ }^{82}$, inquisidor ordinario y vicario $^{83}$ de esta villa de Madrid y su partido, etc.

Por la presente y lo que a nos toca damos licencia para que la tonadilla antecedente, titulada El sistema de los preocupados, se pueda cantar en cualquiera de los teatros cómicos de esta corte mediante haber sido por nos vista y no contiene cosa que se oponga a nuestra santa fe y buenas costumbres, omitiéndose los versos que van rayados. Dado en Madrid, a veinticuatro de abril de mil setecientos ochenta y seis. Dr. Peña. [Rúbrica].

Por su mando, Pedro Landeras y Velasco ${ }^{84}$. [Rúbrica $]^{85}$.

80 Se refiere al lanzamiento de flechas por el dios griego Eros, equivalente del romano Cupido.

81 $\quad$ 2 es el único testimonio que recoge estos breves textos, por lo que el aparato crítico culmina con la transcripción fiel de los mismos según el citado manuscrito. Se han colocado tras el texto porque es el lugar en el que aparecen en el original.

82 Cayetano de la Peña y Granda fue un presbítero que ocupó distintos puestos en la diócesis de Ceuta y, posteriormente, en la archidiócesis de Toledo, de la que llegó a ser vicario eclesiástico de Madrid. En 1790 fue preconizado obispo de Huesca, tras lo cual ingresó en el orden episcopal y se dirigió a su nuevo destino, donde pertemaneció hasta su fallecimiento en 1792.

83 En 1786 la villa de Madrid y la corte pertenecían, eclesiásticamente, a la archidiócesis de Toledo. La capital era regida, bajo la autoridad del arzobispo toledano, por un vicario territorial; en este caso, Peña y Granda. No fue hasta 1886 cuando fue erigida la diócesis de Madrid-Alcalá, elevada a archidiócesis en 1964 y a metropolitana de la provincia eclesiástica de Madrid tras desgajarse las diócesis de Alcalá de Henares y Getafe en 1991.

84 Pedro Landeras y Velasco era miembro de la curia de la vicaría de Madrid.

85 A esta rúbrica sigue, en N2, la indicación «De Cantar», solo presente en dicho ejemplar. 
Madrid, 24 de abril de 1786.

Pase al R. P. Fr. Ángel de Pablo Puerta Palanco ${ }^{86}$ y al corrector D. Ignacio López de Ayala ${ }^{87}$ para su examen y, evacuado, tráigase.

Armona $^{88}$. [Rúbrica].

He leído con cuidado la tonadilla antecedente, titulada El sistema de los preocupados, y enmendada en lo rayado, podrá cantarse. La Victoria de Madrid, a 25 de abril de 1786.

Fr. Ángel de Pablo Puerta Palanco. [Rúbrica].

Señor:

He leído la tonadilla que precede y no hallo reparo en que se cante. Madrid, 25 de abril de 1786.

Ignacio López de Ayala. [Rúbrica].

Madrid, 25 de abril de 1786.

Apruébase y cántese en los términos que se propone por las anteriores censuras.

Armona. [Rúbrica].

\section{Aparato crítico}

\section{1: Que $H$ N1 N2}

2: No $M L$

3: como $H \mathrm{Nl}$ ber como $\mathrm{N} 2 \mathrm{Al} \mathrm{ML}$

4: piensa del delirio $\left[\mathrm{y} \mathrm{bis}^{89}\right] H N 1$ piensa del delirio N2 Piensa...delirio. $M L$

86 El reverendo padre fray Ángel de Pablo Puerta Palanco fue un monje perteneciente a la Orden de los Mínimos, fundada por san Francisco de Paula y aprobada por el papa Sixto IV en 1474. Además de varios cargos en dicha orden, fue revisor de obras dramáticas para la censura.

87 Ignacio López de Ayala el un autor neoclásico que escribió la célebre tragedia Numancia destruida y algunas obras históricas y astronómicas. Corrector de comedias de los teatros públicos de Madrid, fue catedrático de Poética de los Reales Estudios de San Isidro de Madrid y miembro de la Real Academia de la Historia y de la Real Academia de Bellas Artes de San Fernando.

88 José Antonio de Armona y Murga fue un funcionario del Estado ilustrado que desempeñó diferentes puestos en España y América. Carlos III lo nombró corregidor de Madrid en 1777, cargo que ocupó hasta su muerte en 1792. Como Juez Protector de Teatros renovó los coliseos de la corte.

89 Los bises solo están presentes en los testimonios $H$ y $N 1$, que son los únicos que tienen el guion musical de la composición. Cuando $N 2$ y $M L$ quieren indicar la repetición de algún fragmento — generalmente con la reproducción de alguno de esos primeros versos— se desarrolla el texto completo en la edición y se da cuenta en el aparato crítico. 
5: me $\mathrm{HN} N \mathrm{N2}$

6: Me $M L$

7: $\mathrm{Al} M L$

8: Pedantismo N2 Tanto $M L$

9: Tanto $M L$

10: Tanto $M L$

10-11: [tres bises] $\mathrm{H} \mathrm{N1}$

11: [bis] $H$ En $M L$

12: todas $N 2$ Las $M L$

13: Por $M L$

14: Que $M L$

15: q. ${ }^{\text {e }}$ y bis] $H$ [bis] $N 1$ q $^{\mathrm{e}} N 2$

16: me [y tres bises] $H$ me enternezco $\&^{\mathrm{a}}$ [y tres bises] $N 1$ me enternezco $\&^{\alpha}$

N2 Me enternezco, \&c. $M L$

23: principio $M L$

24: pintare $N 1$ N2 Pintaré $M L$

25: q. ${ }^{\mathrm{e}} H$ q $\mathrm{e} 2 \mathrm{El} M L$

26: [bis] $H N 1$ En $M L$

27: el...q. ${ }^{e}$ boi $H$ el...boi $N 1$ q $^{e}$ boi à $N 2$ á $M L$

28: q. ${ }^{e}$ an [y dos bises] $H N 1$ q $^{\text {e }} N 2$ Tiene $M L$ complacer; $M L$

27-28: [bis] N1 N2

28: [dos bises] $N 1$

29: de...q. ${ }^{\mathrm{e}} \ldots$ mas $H$ de...mas $N 1$ De... q ${ }^{\mathrm{e}} \ldots$ mas $N 2$ De...mas $M L$

30: gritarà $H$ gritara $N 1$ Gritara...berlo $N 2$ Gritará...verlo, $M L$

31: q. ${ }^{\mathrm{e}} H$ es es el $N 1 \mathrm{q}^{\mathrm{e}} \ldots$...Preocupados $N 2$ Que $M L$

32: [bis] $H N l^{90}$ Este $M L$

27-32: [bis] $N 1$

33: en...Y Ydea...q. ${ }^{\mathrm{e}} H$ Ydea señores $\mathrm{q}^{\mathrm{e}} N 2$ Señores $M L$

34: yero...objetos q. ${ }^{\text {e }} H$ yero objetos $N 1$ ojetos q ${ }^{\mathrm{e}} N 2$ No...á...sugetos $M L$

35: q. ${ }^{e} H$ preocupacion q. ${ }^{e} N 1$ preocupacion $q^{\text {e }} \ldots \mathrm{Ma}^{\mathrm{d}} N 2$ Pues...preocupacion $M L$

36: q. ${ }^{\mathrm{n}}$ oi $H$ à...oy hansio. ${ }^{a} N 2$ Es...á $M L$

37: q. ${ }^{\mathrm{e}} \mathrm{HN}$ q $\mathrm{q}^{\mathrm{e}} \mathrm{N2}$

38: manifestarà $H$ manifestara $N 2$ Manifestará $M L$

39: q. ${ }^{\mathrm{n}} H$ N1 N2 Quién...tiene $M L$

40: Por...necedad $M L$

41: En $M L$

90 Repite «Este es». 
42: [dos bises] $H N 1$ El $M L$

43: q. ${ }^{\text {e }} \mathrm{H}$ el ignorante q ${ }^{\mathrm{e}}$ quiera $\mathrm{N2}$

44: [bis] H Nl Hombre Docto $M L$

45: De $M L$

46: cafès $H N 2$ Y...Cafés $M L$

45-46: [bis] $\mathrm{H} \mathrm{Nl}$

46: [dos bises] $H$ [bis] $N 1$

47: el Pedante q. ${ }^{\mathrm{e}} H$ Pedante $N 1 \mathrm{q}^{\mathrm{e}} N 2$ Pedante... sábio $M L$

48: opinion [y bis] $H N 1$ quiere...opinion $N 2$ Quiera...opinion $M L$

49: estrangero $H N 1 N 2$ Todo...estrangero alabe $M L$

50: nacion $H N 1$ Y...Nacion. $M L$

49-50: [bis] $H N I$

50: [dos bises] $H$ [bis] $N 1$ able...Nacion $N 2$

51: charlatan q. ${ }^{\mathrm{e}} H$ charlatan $N 1$ El charlatan q ${ }^{\mathrm{e}}$ quisiere $N 2$ Charlatan $M L$

52: [bis] $H N 1$ Ser Dentista $M L$

53: q. ${ }^{\mathrm{e}}$...francès $H$ q. ${ }^{\mathrm{e}} \ldots$ frances $N 1 \mathrm{q}^{\mathrm{e}} \ldots$ frances $N 2$ Diga...Francés $M L$

54: balcon $H$ N1 N2 Muchas...balcon $M L$

53-54: [bis] $\mathrm{H} \mathrm{N1}$

54: [dos bises] $H\left[\right.$ bis] $N I^{91}$

55: Modista N1 Sy...Modista Española N2 Modista Española $M L$

56: [bis] $H N 1$ Dar...á...Tienda $M L$

57: q. ${ }^{\text {e }} H$ Muestra q ${ }^{\mathrm{e}} N 2$ Ponga $M L$

57-58: [bis] $\mathrm{H} \mathrm{Nl}$

58: tienda [y dos bises] $H$ tienda [y bis] $N 1$ tienda $N 2$

59: transpineraicos $H$ Seguid Transpirenaicos $M L$

60: q. ${ }^{\mathrm{e}}$ esto que $\left[\mathrm{y} \mathrm{bis}{ }^{92}\right] H$ que esto que [y bis $\left.{ }^{93}\right] N 1$ q $^{\text {e }} N 2$ Esto $M L$

61: sereis $H N 1 N 2$ Y sereis $M L$

62: q. ${ }^{e}$ de $H$ De...siglo: $M L$

61-62: [bis] $H^{94} \mathrm{Nl}$

63: pongais $H N 1 N 2$ pongais duda, $M L$

64: q. ${ }^{\mathrm{e}} H \mathrm{q}^{\mathrm{e}} \mathrm{N} 2$ Que $M L$

65: q. ${ }^{\text {e }}$ de $H$ que de $N 1$ De $M L$

64-65: [bis] $\mathrm{H} \mathrm{Nl}$

66: Medico q. ${ }^{\mathrm{e}} H$ Medico $N 1$ todo Medico q ${ }^{\mathrm{e}} N 2$ Médico $M L$

67: [bis] $H N 1$ Adquirir $M L$

91 Repite como «bancon».

92 Repite «esto que digo».

93 Repite «esto que digo».

94 Repite como «platones». 
68: Romance $H$ aunq ${ }^{\mathrm{e}} \ldots$ Romance $N 2$ Aunque... Romance $M L$

69: q. ${ }^{\mathrm{e}} .$. latin $H$ latin $N 1$ q ${ }^{\mathrm{e}}$...Latin $N 2$

68-69: [bis] $\mathrm{H} \mathrm{Nl}$

69: [dos bises] $H$ [bis] $N 1$ Diga...Latin $M L$

70: el Peluquero q. ${ }^{\text {e }} H$ Peluquero N1 ML Peluquero q ${ }^{\text {e }} 2$

71: mas estimacion [y bis] H N1 mas estimacion N2 Tener mas estimacion, $M L$

72: señor $H$ Si $M L$

73: llamese monsiur $H$ llamese monsiur [y bis] N1 llamese $N 2$

72-73: [bis] $H N I$

73: [dos bises] $H^{95}$ [bis] $N 1$ Llámese $M L$

74: q. ${ }^{\mathrm{e}} H$ Español q. ${ }^{\text {e }} N 1$ Español q ${ }^{\mathrm{e}} N 2$ Español $M L$

75: qualquier [y bis] $H$ cosa [y bis] $N 1$ qualquier $N 2$ Qualquier $M L$

76: q. ${ }^{\mathrm{e}} H$ sy... q ${ }^{\mathrm{e}} \mathrm{N} 2 \mathrm{Si} M L$

77: q. ${ }^{\mathrm{e}} H$ q. ${ }^{\mathrm{e}}$...Español $N 1$ No...Español $M L$

76-77: [bis] $H N 1^{96}$

77: [dos bises] $H\left[\right.$ bis] $N 1^{97} \mathrm{q}^{\mathrm{e}} \ldots$ Español $N 2$

7898: todo Agente q. ${ }^{\mathrm{e}} H$ Agente $N 1 M L$

79: mas [y bis] $H N l$ Mas $M L$

80: Lacayo $H$ Tenga... Lacayo $M L$

81: jamas $H N 1$ Y $M L$

80-81: [bis] $H N l^{99}$

81: [dos bises] $H$ [bis] $N 1$

82: guardad transpineraicos $H$ Guardad Transpirenaicos $M L$

83: q. ${ }^{\mathrm{e}}$ estos [y bis $\left.{ }^{100}\right] H$ [bis] $N 1$ Estos $M L$

84: q. ${ }^{\mathrm{e}} \ldots \mathrm{q} .{ }^{\mathrm{e}} H \mathrm{q}$. ${ }^{\mathrm{e}} . .$. al que $N 1 \mathrm{q}^{\mathrm{e}}$ al q ${ }^{\mathrm{e}} N 2$ Que $M L$

85: que daran probecho $H$ q. ${ }^{e}$ daran probecho $N 1$ daran probecho $N 2$ Darán provecho: $M L$

84-85: [bis] $H^{101} N 1$

86: q. ${ }^{\mathrm{e}} N 1$ Que $N 2 M L$

95 Repite como «Monsiur».

96 Repite como «que es Español».

97 Repite como «Español».

98 El testimonio $N 2$ es el manuscrito que fue presentado a la censura. Contiene cuatro versos que fueron subrayados, aconsejando su eliminación, pero pueden leerse. Los versos 78 a 81 de $N 2$ son: «Y en fin si asta el Diablo quiere | pruebas de Nobleza hacer | probara al punto nobleza | sy hace ber q es Montañes». Fueron sustituidos por los que se recogen en el texto fijado para esta edición (criterio elegido por suponer la última versión de la obra), que además están presentes en los testimonios $H, N 1$ y $M L$.

99 Repite como «Lacayo».

100 Repite «estos preceptos».

101 Repite como «daràn». 
87: bende $H N 2 \mathrm{El} M L$

88: que por $H$ q. ${ }^{\text {e }}$ por $N 1$ Por $M L$

$90^{102}$ : q. ${ }^{\text {e }}$ esto $H N 1$ Esto $M L$

91: Zelos...Amante $N 2$ zelos $M L$

92: impios $H N 1$ N2 Son...impíos, $M L$

91-92: [tres bises] $H$ [dos bises] $N 1$

92: [bis] $H$ [dos bises] $N 1$

93: q. ${ }^{\mathrm{e}} H$ matando $N 1 \mathrm{q}^{\mathrm{e}}$ matando $N 2$ Que $M L$

94: [bis] H Nl Matan ML

95: q. ${ }^{\mathrm{e}} H$ que $N 1 \mathrm{Q}^{\mathrm{e}} N 2$ Qué $M L$

96: q. ${ }^{\text {e }} H$ que $N 1$ N2 !Qué [sic] $M L$

97: Alma $N 2$ Padece $M L$

98: q. ${ }^{\text {e }}$ a $H$ que a $N 1$ q $^{\text {e }} N 2$ Que $M L$

99: desdichados N1 Aman. ${ }^{\mathrm{s}} N 2$ amantes $M L$

100: buestro $H N 1$ vrō $N 2$ Moderad $M L$

101: q. ${ }^{\text {e }} H N 1$ q $N 2$ Que $M L$

102: q. ${ }^{\mathrm{e}}[\mathrm{y}$ bis $] H$ amo $\left[\mathrm{y}\right.$ bis $\left.^{103}\right] N 1 \mathrm{q}^{\mathrm{e}}$...Amor $N 2$ Que...amor: $M L$

103: trabieso $H N 1 N 2$ Pues $M L$

104: esta $H N 2$ Se $M L$

105: q. ${ }^{\text {e }} H$ q $^{\mathrm{e}} \ldots$ Almas $N 2$ Del $M L$

106: mas $H N 1$ N2 Hace mas $M L$

105-106: [dos bises] $H N I^{104}$

106: [bis] $H N 1$

$\mathrm{M}^{\mathrm{d}}$ y Abril 24 de 786

Vista: Omitiendose los versos raya $\mid$ dos dese Licencia $=$

Nos el D. ${ }^{\mathrm{r}}$ D. ${ }^{\mathrm{n}}$ Cay. ${ }^{\text {no }}$ de la Peña | y Granda Ynqq. ${ }^{\text {or }}$ ordinario y Vicario | de estta villa de Madrid y su Partido \&. ${ }^{\text {a }}$

Por la presente y lo que a Nos toca $\mid$ damos Lizencia para que la $\mid$ tonadilla antez. ${ }^{\text {te }}$ titulada el Siste $\mid$ ma de los preocupados, se pueda $\mid$ cantar en qualquiera de los thea | tros comicos desta corte, mediante | haver sido por nos vista y no con | tiene cosa que se oponga á | nuestra santa fee y buenas cos | tumbres: omitiendose los versos q. ${ }^{\text {| }}$ ban rayados: Dado en Madrid | a veinte y quatro de Abril $\mid$ de mil settez. ochenta y seis =

102 Los versos 89 y 90 no aparecen en el testimonio N2.

103 Repite como «amor», lo que lleva a pensar en que el «amo» que figura en el guion de N1 es una errata debido a la omisión de la última consonante.

104 Repite como «q. ${ }^{e}$ en». 
D. ${ }^{r}$ Peña [Rúbrica]

Por su m. ${ }^{\mathrm{do}}=\mid$ Pedro Landeras $\mid$ Y Velasco [Rúbrica]

Madrid 24 de Abril de 1786.

Pase al R. P. Fr. Angel de Pablo Puerta | Palanco, y al Corrector D. ${ }^{\mathrm{n}}$ Ygnacio Lopez | de Ayala para su examen, y evaquado | trahigase.

Armona [Rúbrica]

He leido con cuidado la tonadilla anteceden- $\mid$ te titulada El Sistema de los Preocupados, y emmen | dada en lo raiado podra cantarse. La victoria de | Madrid a 25 de Abril de 1786

fr. Angel de Pablo Puerta Palanco [Rúbrica]

Señor.

He leído la tonadilla que precede $\mid$ y no hallo reparo en que se can- $\mid$ te. Madrid y Abril 25. de 1786

Ignacio Lopez de Ayala [Rúbrica]

Madrid, 25 de Abril de 1786.

Apruevase y cantese, en los $\mid$ terminos que se propone por las | anteriores Censuras.

Armona [Rúbrica] 